\title{
High-Temperature Oxidation Performance of Mo-Si-B Alloys: Current Results, Developments and Opportunities
}

\author{
Steffen Burk ${ }^{1, a}$ and Hans-Jürgen Christ ${ }^{1, b}$ \\ ${ }^{1}$ Institut für Werkstofftechnik, Universität Siegen, Paul-Bonatz-Str. 9-11, 57068 Siegen, Germany \\ asteffen.burk@uni-siegen.de, ${ }^{b}$ christ@ifwt.mb.uni-siegen.de
}

\section{Key words: Mo-Si-B alloys, oxidation behaviour, selective oxidation}

\begin{abstract}
Ni-base superalloys are approaching the melting point as their fundamental limitation. For high-temperature components one possibility aiming at a further increase of efficiency, e.g. of jet turbines, is the use of refractory metals. Mo as base material is suitable for operating temperatures far beyond $1200^{\circ} \mathrm{C}$. As a consequence of the formation of volatile Mo-oxides, it exhibits no intrinsic oxidation resistance when exceeding $700^{\circ} \mathrm{C}$. Mo-Si-B alloys have melting points around $2000^{\circ} \mathrm{C}$ and retain good mechanical properties and oxidation resistance at very high temperatures. In air, the three-phase Mo-Si-B alloy dealt with in this paper shows excellent oxidation behaviour between $900^{\circ} \mathrm{C}-1300^{\circ} \mathrm{C}$ as a consequence of the formation of a protective silica scale. Below $900^{\circ} \mathrm{C}$, alloys of this class suffer from catastrophic oxidation, leading to an evaporation of Mo-oxide and giving rise to a linear rate law of the weight loss. A protective oxide layer is not formed as a consequence of simultaneous and competitive Mo- and Si-oxide formation. Several approaches are possible to improve the oxidation performance of Mo-Si-B alloys, especially in this moderate temperature range. These include classical alloying, e.g. with $\mathrm{Cr}$ aiming for protective Cr-oxide scales, addition of small amounts of reactive elements for microstructurerefinement as well as selective oxidation of silica in oxygen-deficient atmospheres prior to operation in air. The results presented show promising opportunities and indicate that an oxidation protection from room temperature up to $1300^{\circ} \mathrm{C}$ requires a combination of the suggested approaches.
\end{abstract}

\section{Introduction}

Using refractory metals (RM), ceramic materials or intermetallic compounds for high temperature structural applications has become an ambitious objective in the past decades aiming at endurable temperatures of $1200^{\circ} \mathrm{C}$ and beyond. However, when used as a component, these materials rarely simultaneously satisfy oxidation resistance and structural functionality. Ceramics and intermetallics suffer from brittleness at low temperatures, whereas refractory metals exhibit oxidation problems and poor creep resistance at high temperatures.

Intensive research on Mo-Si-B alloys has been carried out since the mid 1990s. For the Mo-Si-B alloys studied in this work, intermetallic compounds serve as reservoirs for oxidation protection, and a ductile metallic Mo phase assures high fracture toughness. Mo in solid solution $\left(\mathrm{Mo}_{\mathrm{ss}}\right)$ along with the intermetallic compounds $\mathrm{Mo}_{3} \mathrm{Si}$ (A15 crystal structure) and $\mathrm{Mo}_{5} \mathrm{SiB}_{2}$ (T2 crystal structure) was firstly investigated by Berczik [1,2]. Both intermetallics have melting temperatures around $2000^{\circ} \mathrm{C}$ which makes them attractive candidates for high temperature applications. The oxidation behaviour of Mo-Si-B alloys beyond $900^{\circ} \mathrm{C}$ usually consists of two stages. First, the alloy shows a reaction-controlled transient oxidation dominated by the formation of volatile $\mathrm{MoO}_{3}$. This state is accompanied by a high material recession. Steady state oxidation and oxygen-diffusion controlled kinetics is rate controlling, once a continuous silica layer has developed. The scale consists of silica with $\mathrm{B}_{2} \mathrm{O}_{3}$ in solid solution protecting the alloy from further rapid oxidation. Besides minimizing the initial weight loss within the initial oxidation state, the challenge in optimizing the oxidation behaviour of Mo-Si-B alloys lies in the optimization of the intermediate temperature regime of $700^{\circ} \mathrm{C}-900^{\circ} \mathrm{C}$. Within this temperature window, oxidation kinetics does not follow the aforementioned behaviour. Here, kinetics is only reaction-controlled, whereas steady-state oxidation is not achieved. Catastrophic oxidation is observed as a consequence of simultaneous and continuous formation of volatile $\mathrm{MoO}_{3}$ and of silica leading to the degradation of the alloy. 
Based on the oxidation behaviour of conventional Mo-Si-B alloys in air, Fig. 1 lists several methods which seem to be suitable to expand the service temperature window. Classical alloying approaches regarding Mo-Si-B alloys are adding $\mathrm{Cr}$ and/or $\mathrm{Al}$ to form protective $\mathrm{Cr}$ - and/or Al-oxides. Formation of $\mathrm{Al}_{2} \mathrm{O}_{3}$ through alloying with $\mathrm{Al}$ seems promising as well as the formation of Cr-oxide which was shown for single phase $\mathrm{Mo}_{3} \mathrm{Si}$ alloyed with $\mathrm{Cr}$ [3, 4]. For Mo-Si-B alloys, the idea of adding $\mathrm{Cr}$ is to protect the alloy up to $900^{\circ} \mathrm{C}$ through the formation of a Cr-oxide scale and protection through silica takes over for higher temperatures. Alloying with small amounts of reactive elements or their oxide dispersoids is known as micro alloying. The amount of alloying element is insufficient to allow the formation of a corresponding oxide layer. Effects on the oxidation behaviour resulting from the addition of such elements (e.g., $\mathrm{Zr}, \mathrm{La}, \mathrm{C}, \mathrm{Ti}$ ) in order to improve oxide scale adhesion are well known and widely accepted [5,6]. Furthermore, coating strategies such as pack cementation are common techniques but require a complex and time consuming pre-treatment prior to service of the alloy [7]. This is also required for other pretreatment techniques such as pre-oxidation or selective oxidation. The selective oxidation pretreatment is preformed using different gas mixtures prior to service. This kind of pre-oxidation allows oxidation of only thermodynamically stable silica and suppresses the formation of Mo-oxide, depending on the oxygen partial pressure applied.

The aim of the present paper is to give a brief insight into the current research activities undertaken to understand and further improve the oxidation behaviour of Mo-Si-B alloys. It reviews the isothermal oxidation behaviour of Mo-Si-B alloys, effects of alloying approaches and future ideas on expanding the service temperature window.

OPTIMIZATION OF THE OXIDATION PERFORMANCE OF MO-SI-B ALLOYS

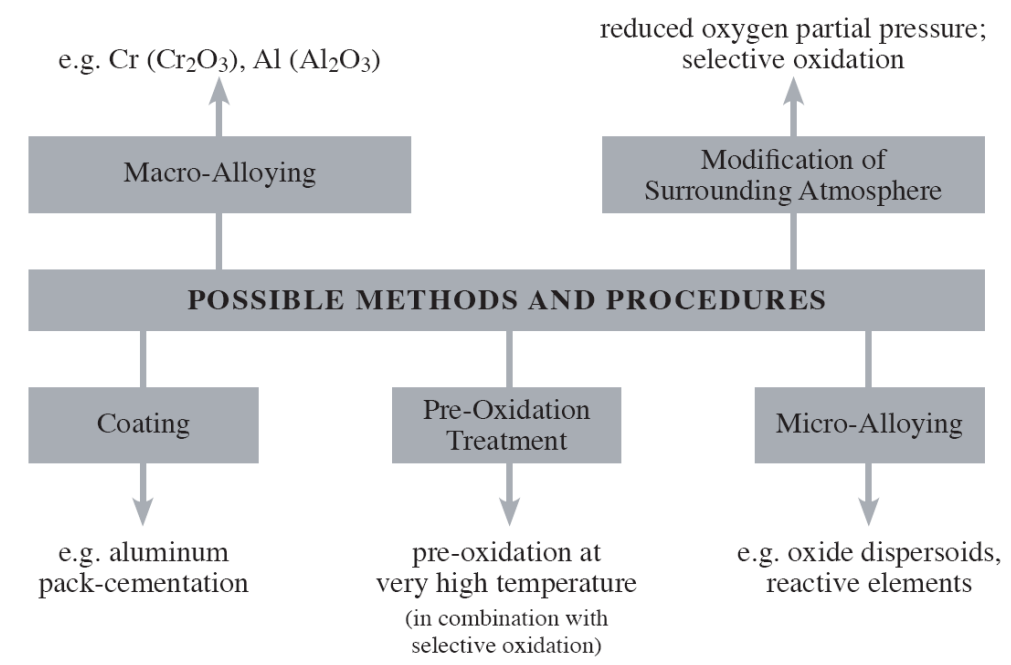

Fig. 1 Possible methods and procedures to improve the oxidation behaviour of Mo-Si-B alloys (based on the reference alloy composition used within this study).

\section{Experimental}

The molybdenum silicide alloys were prepared from elemental powder mixtures of Mo, Si, B and $\mathrm{Cr}$ of $99.95 \%, 99.9 \%, 99.6 \%$ and $99.8 \%$ purity respectively by mechanical alloying in order to enable the formation of a supersaturated $\mathrm{Mo}_{\text {ss }}$ phase. After cold isostatic pressing and sintering under $\mathrm{H}_{2}$-atmosphere, a continuous $\mathrm{Mo}_{\text {ss }}$ matrix exists with embedded intermetallics for those alloys having a volume fraction of Mo solid solution of more than $50 \%$. Compaction of the sintered material was performed by hot-isostatic pressing and-annealing. For the Mo-Si-B-Cr alloys, alloy preparation consisted of isostatic pressing at $200^{\circ} \mathrm{C}$, sintering and annealing. 
The oxidation kinetics was studied under isothermal conditions by continuous thermogravimetric analyses (TGA) using a high resolution $\left(10^{-5} \mathrm{~g}\right)$ Sartorius microbalance. Discontinuous oxidation experiments using a box furnace were carried out for oxide microstructure examination. Surface and cross-sectional scanning electron microscopy (SEM) in secondary-electron (SE) and back-scatteredelectron (BSE) mode was applied. Energy-dispersive X-ray spectroscopy (EDS) was used to qualitatively determine the elements present in the scale. Oxidation samples having the dimensions $10 \times 4 \times 3 \mathrm{~mm}^{3}$ were machined using wire electro-discharge machining (EDM). Prior to oxidation, the samples were ground and polished with $\mathrm{SiC}$ paper down to 1200 grit and ultrasonically cleaned in ethanol. To study the oxide microstructure at different states of oxidation, the samples were placed on alumina crucibles in such a way, that there was only little contact with the alumina. For the TGA measurements, which were carried out up to $100 \mathrm{~h}$, the samples were hung on a platinum wire directly connected to the microbalance. For every temperature and alloy composition, the experiments were carried out at least two times in order to avoid sample to sample variation. Oxidation experiments were performed in the temperature range from $750^{\circ} \mathrm{C}$ up to $1300^{\circ} \mathrm{C}$. In additional experiments, a mixture of $\mathrm{He} / 10 \% \mathrm{H}_{2}$ (vol.\%) was used as reaction atmosphere in a gastight reaction chamber allowing only selective oxidation to suppress Mo-oxide formation. The gas mixture passed over the sample with low velocity at a pressure of 1.1 bar in the viscous gas-flow regime. Table 1 gives the composition of the different alloys used.

Table 1 Nominal chemical composition (in at.\%) of the Mo-Si-B alloys studied.

\begin{tabular}{lcccccc}
\hline & Mo & $\mathbf{S i}$ & $\mathbf{B}$ & $\mathbf{Z r}$ & $\mathbf{L a}_{2} \mathbf{O}_{3}$ & $\mathbf{C r}$ \\
\hline Mo-Si-B & bal & 9 & 8 & - & & - \\
Mo-Si-B-Zr & bal & 9 & 8 & 1 & & - \\
Mo-Si-B-La $\mathbf{O}_{3}$ & bal & 9 & 8 & - & 0,4 & - \\
Mo-Si-B-Cr & bal & 9 & 8 & & & $5,10,15,20,25$ \\
\hline
\end{tabular}

\section{Results and Discussion}

Fig. 2 summarizes the oxidation kinetics of the reference alloy Mo-9Si-8B. The results served as starting point for further optimization of the oxidation performance. The specific sample weight change vs. time is plotted for selected temperatures between $900^{\circ} \mathrm{C}-1300^{\circ} \mathrm{C}$ and yielded two main observations: (1) Stable passivation through silica scale formation occured only beyond $900^{\circ} \mathrm{C}$. At $900^{\circ} \mathrm{C}$ and below, catastrophic oxidation leads to rapid weight loss and sample degradation. (2) The heavy initial weight loss increased with oxidation temperature. At $1100^{\circ} \mathrm{C}$, oxidation behaviour reached a steady state with only marginal weight change, whereas at $1200^{\circ} \mathrm{C}$ as well as at $1300^{\circ} \mathrm{C}$ still appreciable weight loss was observed although passivation through silica is evident. Continuous weight loss is likely to be attributed to volatilization of $\mathrm{B}_{2} \mathrm{O}_{3}$ from the silica since its volatilization rate increases exponentially with temperature beyond $1000^{\circ} \mathrm{C}$.

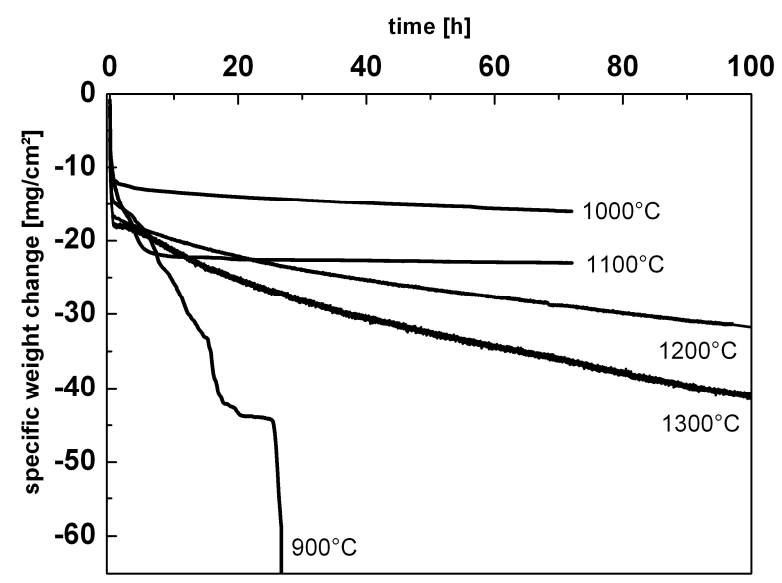

Fig. 2 TGA results for Mo-9Si-8B at $900^{\circ} \mathrm{C}-1300^{\circ} \mathrm{C}$ obtained in tests carried out up to $100 \mathrm{~h}$. 
Oxidation experiments below $900^{\circ} \mathrm{C}$ were carried out in the box furnace because of the heavy weight loss of the sample. The specific weight change of the Mo-9Si-8B sample at $750^{\circ} \mathrm{C}$ was measured to be $-470 \mathrm{mg} / \mathrm{cm}^{2}$ after $72 \mathrm{~h}$ of oxidation and $-94 \mathrm{mg} / \mathrm{cm}^{2}$ at $820^{\circ} \mathrm{C}$. The reason for the unprotective silica scale formation below $900^{\circ} \mathrm{C}$ is depicted in Fig. 3 (a), showing the cross-section of a Mo-9Si-8B sample oxidized at $820^{\circ} \mathrm{C}$ for $7 \mathrm{~h}$. Although silica developed as distinct layer, sealing occurred only locally but not globally all over the sample surface. Global sealing through silica is achieved at $1100^{\circ} \mathrm{C}$, as shown in Fig. 3 (b). At $820^{\circ} \mathrm{C}$, open pathways which were provided within the silica scale allowed oxygen to directly penetrate to the substrate. A continuous Mo-oxide formation with the viscosity of the silica scale being too high to allow fast sealing gives rise to local spallation or pore formation within the silica.

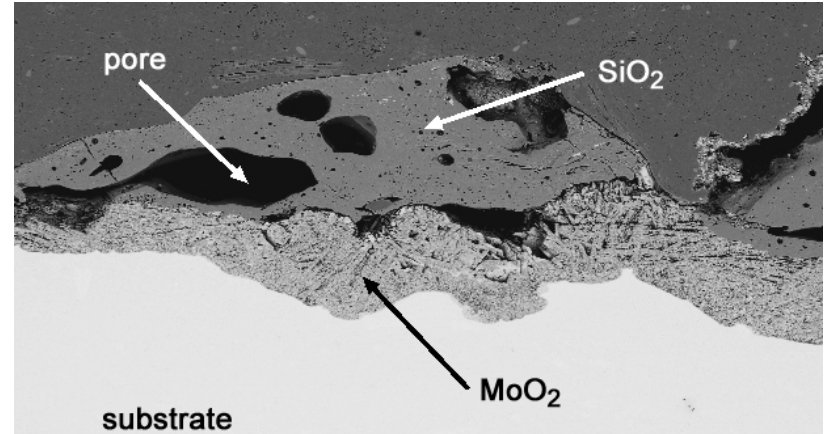

$500 \mu \mathrm{m}$

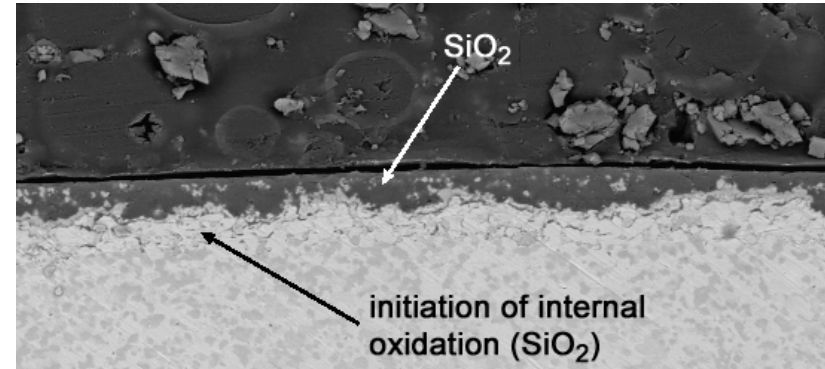

substrate

Fig. 3 (a) Cross-section of Mo-9Si-8B oxidized at $820^{\circ} \mathrm{C}$ for $7 \mathrm{~h}$ (BSE image) (b) Cross-section of Mo-9Si-8B oxidized at $1100^{\circ} \mathrm{C}$ for $72 \mathrm{~h}$ (BSE image).

Controlling the composition of the silica scale (besides its main compounds $\mathrm{SiO}_{2}$ and $\mathrm{B}_{2} \mathrm{O}_{3}$ ) was found to be crucial in manipulating the oxidation behaviour. Whenever minor-element alloying was involved, particles of minor element oxides were found within the silica. In case of Zr-addition, matrix grain refinement was achieved with a direct effect on mechanical properties, such as improved strength and ductility [8]. For the Mo-Si-B alloys of this study it was found that both $\mathrm{Zr}$ and $\mathrm{La}_{2} \mathrm{O}_{3}$ additions have a drastic effect on the oxidation behaviour as well. Two main effects are responsible for a different oxidation behaviour as compared to conventional Mo-9Si-8B. (1) Due to the fine microstructure as a consequence of the grain refinement, silica sealed faster at reduced initial weight loss (shown exemplarily by the TGA results in Fig 4 (a) for $1000^{\circ} \mathrm{C}$ and $1100^{\circ} \mathrm{C}$; initial weight loss reduced to $2 / 3$ and $1 / 4$ compared to the specific weight loss of conventional Mo9Si-8B). (2) Minor element(oxides) acted as glass additives and fluxing agent and yielded a dense and compact silica scale down to $820^{\circ} \mathrm{C}$, as being shown in Fig. 4 (b).
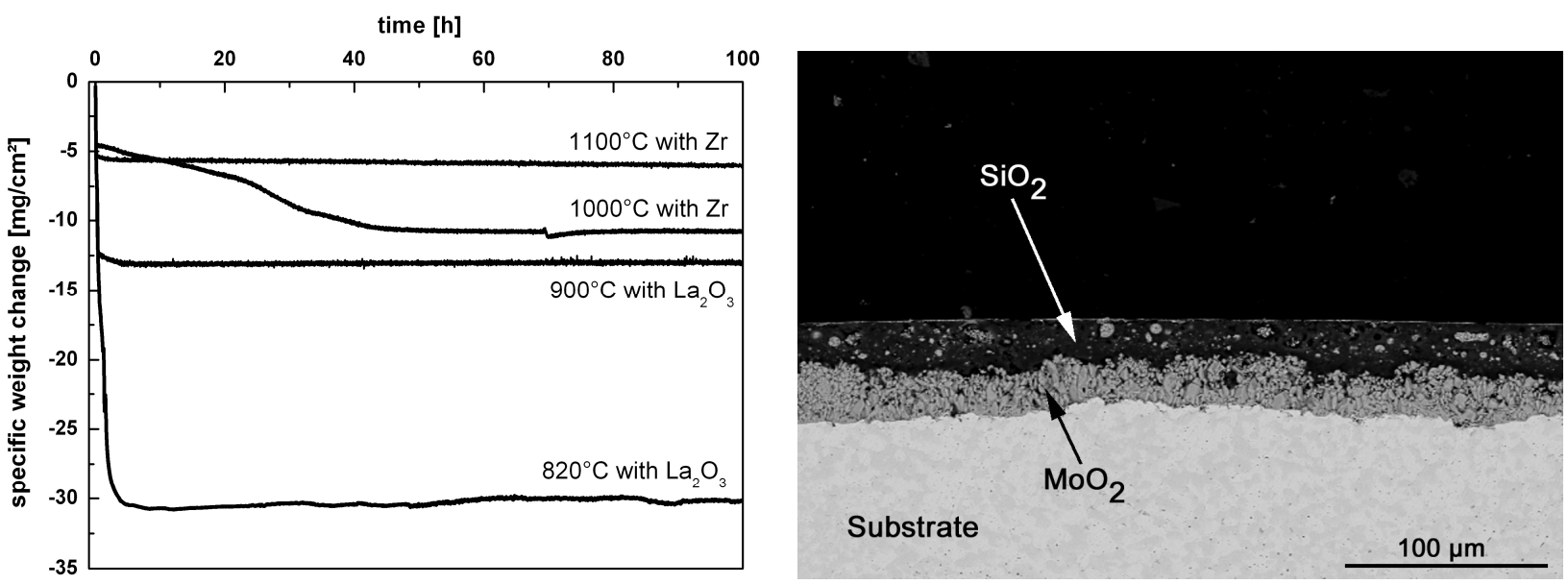

Fig. 4 (a) TGA results for Mo-9Si-8B- $1 \mathrm{Zr}$ at $1000^{\circ} \mathrm{C}$ and $1100^{\circ} \mathrm{C}$ and for Mo-9Si-8B-La $\mathrm{O}_{3}$ at $820^{\circ} \mathrm{C}$ and $900^{\circ} \mathrm{C}$

(b) Cross-section of Mo-9Si-8B- $\mathrm{La}_{2} \mathrm{O}_{3}$ oxidized at $820^{\circ} \mathrm{C}$ for $7 \mathrm{~h}$ (BSE image). 
While alloying with minor additions of reactive elements mainly focuses on improved scale adhesion and silica forming abilities, the intention of macro-alloying of Mo-Si-B alloys is to form a second protective oxide layer besides silica. Chromium seems to be an appropriate candidate, since it provides the advantage (e.g., as compared to Al addition) of an unlimited solubility within the $\mathrm{Mo}_{\text {ss. }}$ This is of special importance when looking for an alloy composition with simultaneously reasonable oxidation as well as mechanical properties. Through the addition of $\mathrm{Cr}$, formation of a third intermetallic phase does not occur, according to thermochemical calculations.

Fig. 5 (a) shows the specific weight change vs. time for the Mo-9Si-8B base alloy composition with varying amounts of $\mathrm{Cr}$ at $750^{\circ} \mathrm{C}$. As expected, without addition of $\mathrm{Cr}$ the alloy experienced the most drastic weight loss, which was about $-100 \mathrm{mg} / \mathrm{cm}^{2}$ after $10 \mathrm{~h}$ of oxidation. Adding $\mathrm{Cr}$ to the alloy system decreased the weight loss. At a Cr concentration of $25 \%$ the sample weight loss entirely disappeares due to the formation of a protective Cr-oxide scale, as shown in Fig 5 (b). $750^{\circ} \mathrm{C}$ represents the lower area of the critical temperature window of $700^{\circ} \mathrm{C}-900^{\circ} \mathrm{C}$. Further tests need to be carried out at higher temperatures. No silica was detected at $750^{\circ} \mathrm{C}$ (Fig. 5 (b)) and the question about the oxide morphology at higher temperatures can not be answered yet.
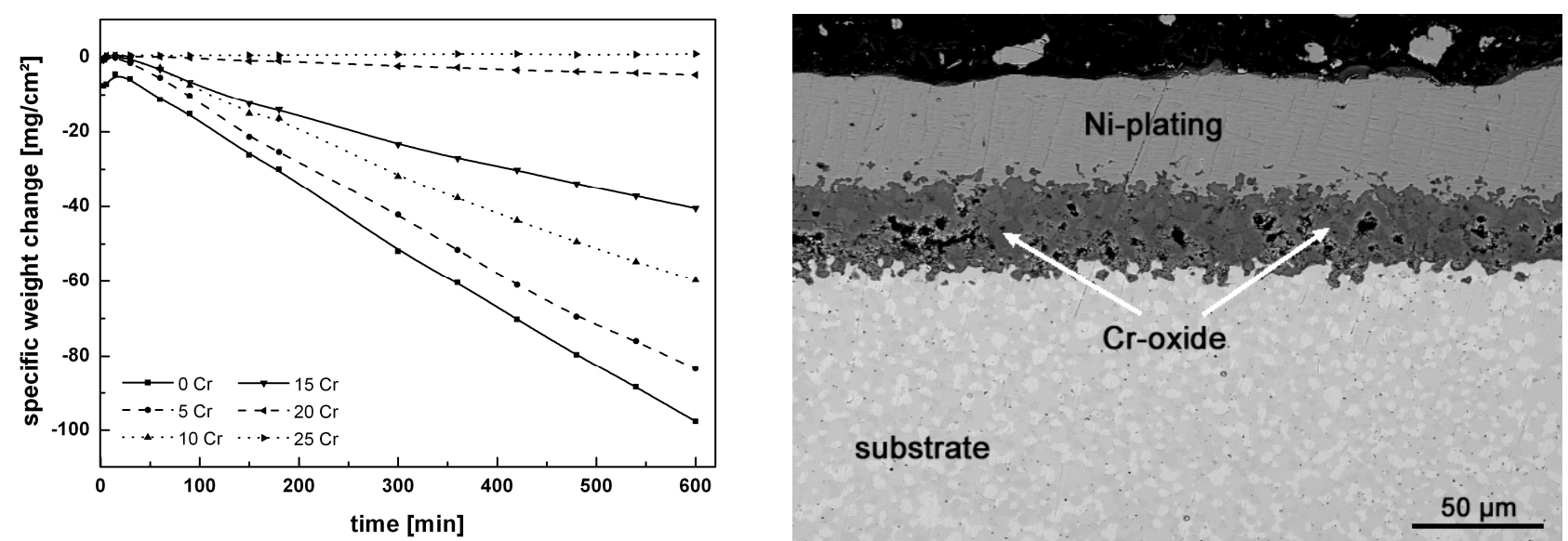

Fig. 5 (a) Specific weight change of Mo-9Si-8B-xCr $(\mathrm{x}=0,5,10,15,20,25 \% \mathrm{Cr})$ at $750^{\circ} \mathrm{C}$ for $10 \mathrm{~h}$ (b) Cross-section of Mo-9Si-8B-25Cr oxidized at $750^{\circ} \mathrm{C}$ for $10 \mathrm{~h}$ (BSE image).

The main reason for applying a pre-oxidation treatment under reduced oxygen conditions in case of Mo-Si-B alloys is to reduce or completely avoid the weight loss of the sample due to volatile Mooxide formation, since the volatile Mo-oxide formation remains one of the critical issues about Mo$\mathrm{Si}-\mathrm{B}$ alloys. In the $\mathrm{He}-\mathrm{H}_{2}$ gas atmosphere applied, any formation of Mo-oxides is completely suppressed, since the oxygen partial pressure under the conditions used lies below the dissociation pressure of Mo-oxide formation. Only $\mathrm{SiO}_{2}$ as well as $\mathrm{B}_{2} \mathrm{O}_{3}$ are thermodynamically stable and selectively oxidized under the testing conditions.

Fig. 6 (a) shows the TGA results at reduced oxygen partial pressure at different temperatures for a duration of $100 \mathrm{~h}$. The characteristic oxidation behaviour was a weight gain kinetics of the sample during exposure in the $\mathrm{He}-\mathrm{H}_{2}$ gas atmosphere which can be considered as being parabolic. Silica formed as an outer scale at the flat oxide/substrate interface exhibiting droplet-like structures, shown in Fig. 6 (b). Parallel to the droplet formation, internal oxidation of silicon was observed, similar to the oxidation behaviour in air. For further oxidation experiments in air the idea is to yield a silica scale through pre-oxidation at reduced oxygen content which is then suitable to resist further oxidation in air. The main advantage, as compared to a coating strategy, is the intrinsic growth of the silica scale from the base alloy as well as the usability of the method for large structures. 

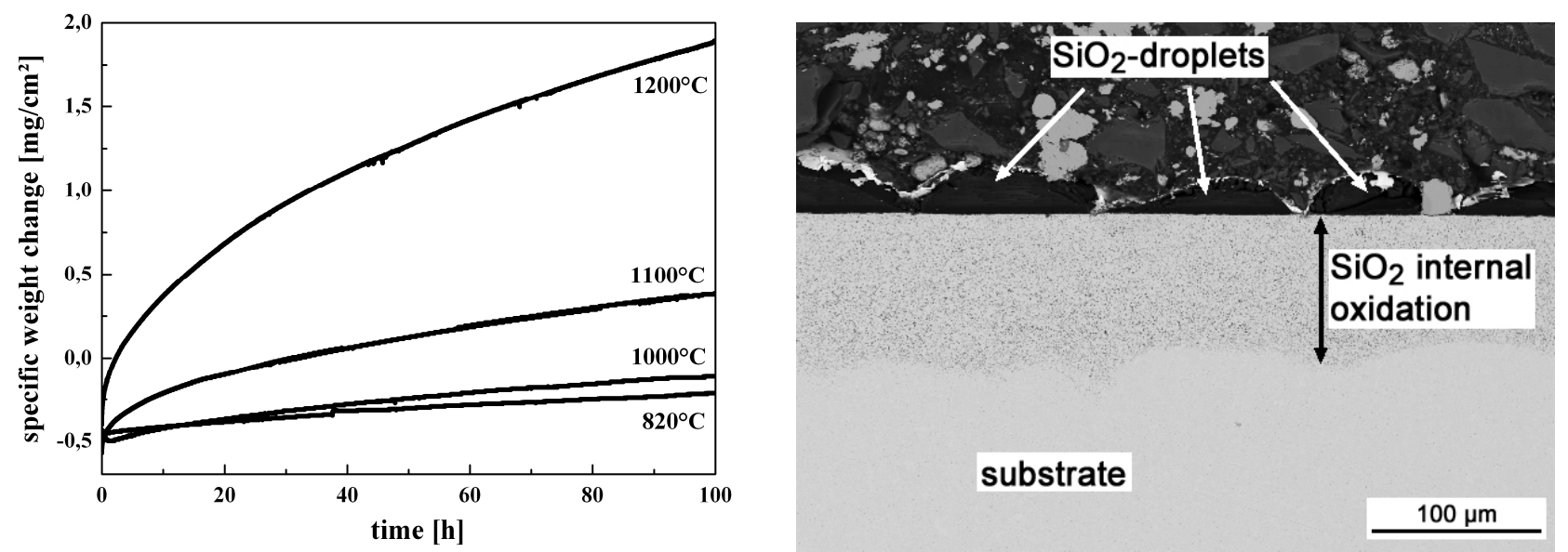

Fig. 6 (a) TGA results for Mo-9Si-8B-1Zr oxidized at $820^{\circ} \mathrm{C}, 1000^{\circ} \mathrm{C}, 1100^{\circ} \mathrm{C}$ and $1200^{\circ} \mathrm{C}$ at decreased oxygen partial pressure (b) Cross-section of Mo-9Si-8B-1Zr oxidized at $1200^{\circ} \mathrm{C}$ and decreased oxygen partial pressure for $100 \mathrm{~h}(\mathrm{BSE}$ image).

\section{Summary}

The results reported in this paper show promising opportunities for an enhancement of the oxidation resistance of $\mathrm{Mo}-\mathrm{Si}-\mathrm{B}$ alloys and indicate that an oxidation protection from room temperature up to $1300^{\circ} \mathrm{C}$ requires a combination of the approaches suggested. The main conclusions which can be drawn of the oxidation behaviour of Mo-9Si-8B and its alloyed variants used in this investigation are:

1.) Conventional three phase Mo-9Si-8B alloys show the best oxidation performance in the temperature range of $1000^{\circ} \mathrm{C}-1300^{\circ} \mathrm{C}$.

2.) Minor element additions, e.g. $\mathrm{Zr}$ and $\mathrm{La}_{2} \mathrm{O}_{3}$ are useful to control the fluxing abilities of the silica scale at selected temperatures.

3.) Additional protection through macro-alloying with $\mathrm{Cr}$ requires $20-25 \%$ of $\mathrm{Cr}$ in order to form stable Cr-oxide scales.

4.) Selective oxidation in oxygen-deficient atmospheres yields in the formation of an outer silica scale which might be useful upon further exposure in air.

\section{Acknowledgement}

Financial support of Deutsche Forschungsgemeinschaft (DFG) in the framework of the Research Group "Beyond Ni-Base Superalloys" is gratefully acknowledged.

\section{References}

[1] D.M. Berczik, U.S. Patent no. 5,595,616, (East Hartford, United Technologies Corp., 1997).

[2] D.M. Berczik, U.S. Patent no. 5,693,616, (East Hartford, United Technologies Corp., 1997).

[3] S. Ochiai, Intermetallics 14, 1351 (2006).

[4] S. Paswan, R. Mitra, and S. K. Roy, Intermetallics 15, 1217 (2007).

[5] D. P. Whittle, J. Stringer, Phil. Trans. Roy. Soc. London A295, 309 (1980).

[6] B. A. Pint, J. Am. Ceram. Soc. 86, 686 (2003).

[7] F. Rioult, N. Sekido, R. Sakidja, and J. H. Perepezko, J. Electrochem. Soc. 154, C692 (2007).

[8] H. Saage, M. Krüger, D. Sturm, M. Heilmaier, J.H. Schneibel, E. George, L. Heatherly, Ch. Somsen, G. Eggeler, Y. Yang, Acta Materialia 57, 13, (2009). 